\title{
Postural drainage and gastro-oesophageal reflux in infants with cystic fibrosis
}

\author{
Brenda M Button, Ralf G Heine, Anthony G Catto-Smith, Peter D Phelan, Anthony \\ Olinsky
}

Royal Children's Hospital, Melbourne: Department of Physiotherapy B M Button

Department of Gastroenterology R G Heine

A G Catto-Smith

Department of Thoracic Medicine P D Phelan ${ }^{\star}$

A Olinsky

Department of Paediatrics, University of Melbourne P D Phelan ${ }^{\star}$

Correspondence to: Dr Anthony G Catto-Smith, Department of Gastroenterology, Royal Children's Hospital, Flemington Road, Parkville, Victoria 3052, Australia.

Accepted 8 November 1996

\begin{abstract}
Gastro-oesophageal reflux is increased in cystic fibrosis and it is possible that postural drainage techniques may exacerbate reflux, potentially resulting in aspiration and further impairment of pulmonary function.

Aim-To evaluate the effects of physiotherapy with head down tilt (standard physiotherapy, SPT) on gastrooesophageal reflux and to compare this with physiotherapy without head down tilt (modified physiotherapy, MPT).

Method-Twenty (mean age 2.1 months) infants with cystic fibrosis underwent 30 hour oesophageal pH monitoring during which SPT and MPT were carried out for two sessions each on consecutive days.

Results-The number of reflux episodes per hour, but not their duration, was significantly increased during SPT compared with MPT (SPT $2.5(0.4) v$ MPT 1.6 $(0.3), p=0.007)$ and to background (1.1 $(0) 1,. p=0.0005)$. Fractional reflux time was also increased during SPT (11.7 (2.6)\%) compared with background (6.9 (1.3) $\%, p=0.03)$ but not compared with MPT (10.7 (2.7)\%). There was no significant difference between MPT and background for number of reflux episodes, their duration, or fractional reflux time. Conclusion-SPT, but not MPT, was associated with a significant increase in gastro-oesophageal reflux in infants with cystic fibrosis.

(Arch Dis Child 1997;76:148-150)
\end{abstract}

Keywords: gastro-oesophageal reflux; postural drainage; cystic fibrosis; $\mathrm{pH}$ monitor.

Antibiotics and chest physiotherapy have been associated with significant improvements in the survival of patients with cystic fibrosis. ${ }^{1}$ The main aim of chest physiotherapy in cystic fibrosis is to assist in the removal of tenacious pulmonary secretions. Postural drainage (including head down tilt) and manual techniques of percussion and vibrations have been conventional mainstays for patients in many cystic fibrosis specialist centres.

Gastro-oesophageal reflux appears to be increased in patients who have cystic fibrosis. ${ }^{2}{ }^{3}$ Estimates of the incidence of pathologically increased reflux vary between $35-81 \% .^{45}$ Refluxed gastric contents may potentially impair pulmonary function through microaspiration and reflex spasm of the bronchi and glottis. ${ }^{6}$ Stringer et al documented an association between the presence of increased reflux and impaired pulmonary function.

Chest physiotherapy has been reported to exacerbate gastro-oesophageal reflux in patients with non-cystic fibrosis lung disease. ${ }^{8}$ Foster et al, in an abstract published in 1983, described an association between chest physiotherapy and gastro-oesophageal reflux in a small group of older children with cystic fibrosis. ${ }^{9}$ Subsequent authors have recommended that postural drainage in the downward chest tilted position should not be used in patients with symptomatic gastro-oesophageal reflux. ${ }^{10}$

We have recently identified a small group of adolescents with cystic fibrosis who had both rapidly deteriorating pulmonary function and symptoms of reflux during postural drainage. ${ }^{11}$ Cessation of postural drainage and the start of upright positive expiratory pressure treatment was associated with abolition of symptoms of physiotherapy related reflux, significant improvements in pulmonary function, and decrease in hospital admissions. However, despite these observations, the relationship between postural drainage and gastro-oesophageal reflux in children with cystic fibrosis has not been studied adequately in patients before the development of significant lung disease.

Since the introduction of statewide newborn screening for cystic fibrosis in 1989, the diagnosis is now usually made in the neonatal period and daily chest physiotherapy started at around 6 weeks of age. These infants are usually free from respiratory symptoms.

\section{Aim}

The aims of our study were twofold. We wished to establish whether, in newly diagnosed infants with cystic fibrosis, before the development of significant lung disease: (1) standard physiotherapy (with postural drainage including $30^{\circ}$ head down tilt, percussion, and vibrations; SPT) resulted in a significant increase in acid reflux into the oesophagus, and (2) modified chest physiotherapy (MPT), which did not incorporate head down tilt, was less likely to result in significant gastrooesophageal reflux.

\section{Subjects and methods} SUBJECTS

Twenty two consecutive infants with newly diagnosed cystic fibrosis were invited to participate in the study. Two parents declined so 20 infants were recruited. Fifteen had been 
Table 1 Chest physiotherapy and oesophageal pH monitoring; values are mean (SE)

\begin{tabular}{|c|c|c|c|c|c|c|c|}
\hline & \multicolumn{4}{|l|}{ Data } & \multicolumn{3}{|l|}{ Statistical comparison ${ }^{\star}$} \\
\hline & Total & Background & $S P T$ & $M P T$ & SPT v background & $S P T v M P T$ & $M P T$ v background \\
\hline Mean No of episodes/hour & $1.2(0.2)$ & $1.1(0.1)$ & $2.5(0.4)$ & $1.6(0.3)$ & $\begin{array}{l}1.3(0.3) \\
\mathrm{p}=0.0005\end{array}$ & $0.9(0.3) \quad \mathrm{p}=0.007$ & $0.5(0.3) \mathrm{p}=0.10, \mathrm{NS}$ \\
\hline $\begin{array}{l}\text { Mean duration of episodes } \\
\text { (min) }\end{array}$ & $3.3(0.5)$ & $4.3(0.9)$ & $2.4(0.4)$ & $3.5(1.0)$ & $\begin{array}{l}1.9(0.9) \\
p=0.0005\end{array}$ & $1.1(0.9) \mathrm{p}=0.21, \mathrm{NS}$ & $0.8(1.3) \mathrm{p}=0.10, \mathrm{NS}$ \\
\hline Fractional reflux time (\%) & $5.6(0.8)$ & $6.9(1.3)$ & $11.7(2.6)$ & $10.7(2.7)$ & $4.8(2.0) \mathrm{p}=0.03$ & $1.0(1.6) \mathrm{p}=0.53, \mathrm{NS}$ & 3.8 (2.4) $\mathrm{p}=0.13, \mathrm{NS}$ \\
\hline
\end{tabular}

^ Difference of mean (SE of difference).

diagnosed through neonatal screening by blood immune reactive trypsin and four presented with meconium ileus.

Detailed verbal and written information regarding the study were provided to parents before obtaining informed written consent. Approval for the study was obtained from the ethics in human research committee of the Royal Children's Hospital.

PH MONITORING

After the diagnosis of cystic fibrosis and parental counselling, the infants underwent prolonged oesophageal $\mathrm{pH}$ recordings (30 hours) using an ambulatory system (Digitrapper Mark III, Synectics, Sweden) with antimony $\mathrm{pH}$ electrodes. The tip of the $\mathrm{pH}$ probe was sited at $87 \%$ of the distance from the nares to the lower oesophageal sphincter using a nomogram related to body height. ${ }^{12}$ The position of the probe was confirmed by the change in acidity on withdrawal from the stomach, and by radiology if necessary. The number and duration of reflux episodes less than $\mathrm{pH} 4.0$ and lasting longer than 15 seconds were recorded. Fractional reflux time, which represented the proportion of the total time of the recording for which oesophageal $\mathrm{pH}$ was less than 4.0 was calculated. Meals, activities, physiotherapy sessions, and posture were recorded in a diary.

Results for oesophageal $\mathrm{pH}$ recordings were analysed for the 30 hour period of the study and then expressed as 'per hour'. Physiotherapy periods were compared with 'background'. Background excluded meals and the first two postprandial hours, and physiotherapy sessions.

The number of reflux episodes and the fractional reflux time were calculated for each of the positions during SPT and MPT and compared with the corresponding background time.

CHEST PHYSIOTHERAPY

Chest physiotherapy was carried out by the senior thoracic physiotherapist (BMB), who was blinded to the results of the oesophageal $\mathrm{pH}$ recordings. Oesophageal $\mathrm{pH}$ was recorded for each patient during four sessions of chest physiotherapy. These four sessions consisted of two sessions of SPT and two sessions of MPT. Each session of physiotherapy consisted of four eight minute periods of active physiotherapy with rest periods of two to three minutes between each change of position.

SPT:

- Supine horizontal

- Prone with $30^{\circ}$ head down tilt

- Right lateral with $30^{\circ}$ head down tilt
- Left lateral with $30^{\circ}$ head down tilt

MPT:

- Supine with $30^{\circ}$ head up tilt

- Prone horizontal

- Right lateral horizontal

- Left lateral horizontal

Manual techniques:

Cycles of percussion and vibrations with short intervening rest periods were carried out in the same way in each of the four positions at each session.

SPT and MPT were carried out in a standard sequence for each patient: day 1 , MPT in the morning, SPT in the afternoon; day 2, SPT in the morning, MPT in the afternoon. The order of the four positions was randomised during each of the four sessions. Chest physiotherapy sessions were carried out at least two hours after meals.

STATISTICAL ANALYSIS

Data are presented as mean (SE). Student's paired $t$ test was used for comparison between different physiotherapy techniques for individual patients. Statistical significance was accepted for $\mathrm{p}<0.05$.

\section{Results}

The mean age of the infants at the time of study was 2.1 months (range 3-20 weeks). Ten were male.

Three infants (15\%) had a pathologically increased fractional reflux time (FRT) that was greater than $10 \%$. The rest (17) had an FRT which was within normal limits for age; six $(30 \%)$ had a FRT between $5-10 \%$ and 11 $(55 \%)$ had an FRT $5 \%$ or less. Data from the oesophageal $\mathrm{pH}$ recordings are summarised in table 1 .

SPT

SPT was associated with a significant increase in the number of episodes of gastrooesophageal reflux and the fractional reflux time compared with background. The mean duration of reflux episodes during SPT were significantly shorter than during the background recording.

MPT

The number of reflux episodes, their duration, and the fractional reflux time during MPT were not significantly different from background. The number of reflux episodes during MPT was significantly less than during SPT, but there was no significant difference between the duration of reflux episodes for MPT compared with SPT or the fractional reflux time. 


\section{Discussion}

A standard regimen of physiotherapy (SPT), which included head down tilt, was associated with a significant increase in the number of episodes of gastro-oesophageal reflux. These increased episodes of reflux were on average much shorter during SPT. A modified regimen (MPT) which avoided head down tilting was not associated with either a significantly increased number of reflux episodes or altered duration compared with background.

Vandenplas et al have shown that chest physiotherapy using postural drainage, percussion, and vibrations resulted in an increase in the number of reflux episodes. ${ }^{8}$ This increase in reflux episodes during physiotherapy was present in healthy control infants, infants with gastro-oesophageal reflux disease, and in infants with acute infectious respiratory disease. There was no evidence of a temporal correlation between provoked coughing during physiotherapy and episodes of gastro-oesophageal reflux. It was hypothesised that the increase in reflux was due to increased negative intrathoracic pressure resulting from physiotherapy. The physiotherapy positions used during the study of Vandenplas et al were either flat, or at $30^{\circ}$ head down tilt. The role of position was not examined.

Our study demonstrated a reduced number of reflux episodes when $30^{\circ}$ head up was added to all physiotherapy positions so that the subjects were now at least flat or head up.

Posture is known to have a substantial impact on the frequency of transient lower oesophageal sphincter relaxations. These relaxations, rather than low basal sphincter pressure or increased intragastric pressure are thought to be the predominant mechanism of increased gastro-oesophageal reflux in patients who develop reflux oesophagitis. ${ }^{13}$ Cucchiara et al showed that transient lower oesophageal sphincter relaxations were the predominant mechanism of reflux in older children with cystic fibrosis. ${ }^{14}$ The frequency of transient lower oesophageal sphincter relaxations is significantly less in the supine/recumbent positions compared with upright, ${ }^{15}$ but little is known of their frequency in the head down position. The basis for this posture related variation is not clear.

Clearance of oesophageal acid also varies with posture, clearance of refluxate being more delayed in the recumbent posture. The significance of our finding of enhanced oesophageal clearance of acid during head down positions needs to be further evaluated.

It is not yet clear which factors are important in the development of reflux induced pulmonary disease. Theoretically, aspiration of large volumes of refluxate, or even 'microaspiration' may result in lung disease. ${ }^{16}$ Another mechanism by which reflux may contribute to respiratory disease is through reflex bronchospasm, apnoea, or glottic spasm. There is evidence to suggest that the development of reflux induced coughing in adults is proportional to the number of reflux episodes and also to impaired clearance of oesophageal acid. ${ }^{17}$ However, for oesophagopharyngeal reflux and aspiration to occur, refluxate must pass through the upper oesophageal sphincter. Abrupt, brief relaxations of the upper oesophageal sphincter have been observed during oesophageal distension with refluxate. ${ }^{18}$ Potentially, these would appear to be important prerequisites for the development of reflux induced lung disease. However, the mechanisms which control and disturb upper oesophageal competency have not yet been adequately defined.

We have demonstrated an increased number of reflux episodes in head down postural positions adopted during chest physiotherapy. Whether or not this is a factor that may contribute to the progression of lung disease in patients with cystic fibrosis remains to be determined. A modified physiotherapy regimen, which did not involve head down tilting, was not associated with increased gastrooesophageal reflux. This may be a more appropriate technique for chest physiotherapy in infants with cystic fibrosis. The authors thank Mrs Dianne Simpson, gastroenterology
nurse, Gastroenterology Department, for her invaluable assistnurse, Gastroenterology Department,
ance with oesophageal pH monitoring.

1 Mulherin D, FitzGerald M. Cystic fibrosis in adolescents and adults. The coming of age of cystic fibrosis. Dig Dis and adults. The

2 Scott RB, O'Loughlin EV, Gall DG. Gastroesophageal reflux in patients with cystic fibrosis. F Pediatr 1985;106: 223-7.

3 Feigelson J, Sauvegrain J. Reflux gastro-oesophagien dans la mucoviscidose. Nouvelle Presse Medicale 1975;4:2729-30.

4 Vinocur CD, Marmon L, Schidlow DV, Weintraub WH. Gastroesophageal reflux in the infant with cystic fibrosis. Am F Surg 1985;149:182-6.

5 Malfroot A, Dab I. New insights on gastro-oesophageal reflux in cystic fibrosis by longitudinal follow up. Arch Dis Child 1991;66:1339-45.

6 Orenstein SR, Orenstein DM. Gastro-oesophageal reflux and respiratory disease in children. $\mathcal{F}$ Pediatr 1980:97:22449.

7 Stringer DA, Sprigg A, Juodis E, et al. The association of cystic fibrosis, gastroesophageal reflux, and reduced pulmonary function. Can Assoc Radiol f 1988;39:100-02.

8 Vandenplas Y, Diericx A, Blecker U, Lanciers S, Deneyer $\mathrm{M}$. Esophageal pH monitoring data during chest physiM. Esophageal $\mathrm{pH}$ monitoring data during chest
otherapy. F Pediatr Gastroenterol Nutr 1991;13:23-6.

9 Fotherapy. F Pediatr Gastroenterol Nutr 1991;13:23-6. monitoring in children with cystic fibrosis: association of chest physical therapy to gastroesophageal reflux. Pediatr Res 1983;17:118A.

10 Webber BA, Pryor JA. Physiotherapy for respiratory and cardiac problems. London: Churchill Livingstone, 1993:127. 11 Button BM, Heine RG, Catto-Smith AG, Phelan PD. Postural drainage exacerbates gastroesophageal reflux in patients with lung disease; is positive expiratory pressure a better alternative? Pediatr Res 1994;36:47A.

12 Strobel CT, Byrne WJ, Ament ME, Euler AR. Correlation of esophageal length in children with height: application to the Tuttle test without prior esophageal manometry. F Pediatr 1979;94:81-4.

13 Mittal RK, Holloway RH, Peragin R, Blackshaw LA, Dent J. Mittal RK, Holloway RH, Peragin R, Blackshaw LA, Dent J.
Transient lower esophageal sphincter relaxation. GastroenTransient lower esophage

14 Cucchiara S, Santamaria F, Andreotti MR, et al. MechaCucchiara S, Santamaria F, Andreotti MR, et al. Mecha-
nisms of gastro-oesophageal reflux in cystic fibrosis. Arch

15 Freidin N, Mittal RK, McCallum RW. Does body posture affect the incidence and mechanism of gastro-oesophageal reflux. Gut 1991;32:133-6.

6 Orenstein SR. Gastroesophageal reflux. Curr Probl Pediatr 1991;21:193-241

17 Ing AJ, Ngu MC, Breslin AB. Chronic persistent cough and clearance of esophageal acid. Chest 1992;102:1668-71.

18 Willing J, Davidson GP, Dent J, Cook I. Effect of gastro-oesophageal reflux on upper oesophageal sphincter motility in children. Gut 1993;34:904-10. 